Research Article

\title{
Waterflood Management Using Hybrid Approach of Streamline-Based Interwell Flux Information and Finite Volume Reservoir Simulation
}

\author{
Zhouyuan Zhu $\left(\mathbb{D},{ }^{1}\right.$ Zhengdong Lei, ${ }^{2}$ and Zhangxin Chen $\mathbb{D}^{1}$ \\ ${ }^{1}$ China University of Petroleum, Beijing, China \\ ${ }^{2}$ Research Institute of Petroleum Exploration and Development, PetroChina, Beijing, China \\ Correspondence should be addressed to Zhouyuan Zhu; zhuzy02@cup.edu.cn
}

Received 30 April 2018; Accepted 2 August 2018; Published 11 November 2018

Academic Editor: Dan Ma

Copyright (C) 2018 Zhouyuan Zhu et al. This is an open access article distributed under the Creative Commons Attribution License, which permits unrestricted use, distribution, and reproduction in any medium, provided the original work is properly cited.

In this work, we implement new software for improved waterflood management by combining classical finite volume reservoir simulation together with streamline tracing and corresponding interwell flux evaluations to optimize waterflood performance. We have introduced two basic modules here: a commercial reservoir simulator and our own streamline tracing and waterflood management program. Waterflood simulation is performed for a certain time span until simulation is paused, and the streamline tracing program is called to calculate interwell fluxes and adjust new well rates for better waterflood performance. The simulation continues afterwards until the next tracing and adjustment point is reached. The two modules work iteratively. The streamline tracing program is designed to trace streamlines on a compressible velocity field and a general corner point grid system with nonneighboring connections. The new injection rates are adjusted according to each well's injection efficiency calculated from interwell multi-phase fluxes. Streamline tracing is performed successfully not only on simple geometry corner point grid cases, but also on heavily faulted realistic reservoirs under waterflood. After readjusting injection rates multiple times during the simulation, we typically observe a reduction in field water cut of up to $5 \%$ and an increase in oil recovery in our test cases. Interwell flux information serves as effective diagnostic tools to identify injector-producer pairs with large amount of water cycling. All simulations conducted here are rigorously finite volume based, which takes into account the full physics of nonadvective processes such as gravity and capillary effects. In conclusion, we have implemented a streamline-based waterflood management program which works iteratively and cooperatively with a commercial reservoir simulator, without switching to streamline simulation. It provides an effective solution for improving oil recovery in brown fields by combining the rigorous mathematical nature of finite volume simulation and the power of streamline-based flood management.

\section{Introduction}

Streamline simulation, which is particularly effective in solving large, geologically complex and heterogeneous subsurface porous media flow problems, serves as an effective and complementary technology to traditional Eulerian finite volume-based simulation [1]. Traditionally, it is suited for situations where flow is dictated by well rates and positions, reservoir structure, heterogeneity and fluid mobility, that is, advection dominated flow. By utilizing the numerical method of operator splitting, streamline simulation has been extended to include capillary and gravity effects $[2,3]$. Although initially designed for incompressible multiphase flow problems, streamline simulation has also been upgraded to model compressible systems in recent years [4-6]. Modern-day streamline simulation can not only solve black oil or first contact miscible problems [1], but also complex reservoir recovery processes such as polymer flooding $[7,8]$, compositional gas injection [9], and thermal recovery $[5,6,10]$. Recovery in fractured reservoirs could be modeled using the streamline method through a dual porosity/permeability approach [11-14].

Streamline simulation also brings addition reservoir engineering information to the identification of waterflood 
patterns, well pair connections, and areas of flood inefficiency beyond standard surveillance techniques $[15,16]$. By calculating interwell multiphase fluxes using streamlines connecting between injectors and producers, streamline simulation can identify how much oil production comes from the pressure support from a certain injector, which quantitatively generates the waterflood efficiency of each injector/producer pair. With this important information, adjustment of injection/production rates can be made, with the goal of reducing water cycling, increasing oil recovery and improving flood management $[15,16]$. This technique has been successfully deployed to reservoir models for oil fields under waterflood [17], fractured low-permeability reservoir [18], or even polymer flood management [7]. Recently, a set of advanced optimization algorithms have also been developed to rigorously search for the optimum injection/production rates using streamline-based well pair flood efficiencies [19].

Streamline simulation, of course, is not the panacea for all reservoir engineering problems. Streamline simulation inherently does not guarantee mass balance, since fluid transport is calculated along the streamlines rather than the stationary original grid. Mapping errors (source of mass balance error) occur when mapping saturations from the original grid to and from the streamlines within a global time step. For cases with strong nonadvective effects, that is, gravity segregation and capillary, situations where we see frequent changes in well controls, systems with large compressibility, and also historically inherited finite volume simulation models, the relative benefits of using streamline simulation may be limited $[1,6]$. In fact, for processes with strong nonadvective forces, streamline simulation may introduce large numerical errors through operator splitting that decouples the advective and nonadvective forces. Therefore, there is a need to combine the merits and power of streamline-based interwell connectivity and waterflood management, together with the wider applicable range and rigorous mathematical treatment of nonadvective forces, compressibility, and frequently changing well controls in classical finite volume reservoir simulation. If this combination is realized successfully, it will also save the work load for simulation model data transfer between finite volume and streamline simulators, which is often tedious in practice.

In this work, we introduce a novel software implementation, which uses the multiphase velocity field from a classical finite volume reservoir simulator for streamline tracing and interwell flux calculations. The flood efficiencies of each injector/producer pair are then used to further determine the future injection/production rates of each well in order to achieve improved waterflood performance. We show improved oil recovery and waterflood management by combing the advantages of streamline-based flux information to optimize waterflood and the more rigorous and general purpose nature of finite volume simulation.

\section{Implementation}

A new in-house software package is designed and implemented in this work. The software calls commercial finite volume-based simulator Eclipse to conduct reservoir simulation. At the same time, we trace streamlines based on the multiphase velocity field outputted from Eclipse, at certain adjustment points during the entire simulation. Based on the interwell connectivity and injection efficiencies calculated from streamline tracing, we make well rate adjustments accordingly for improved waterflood, after which the finite volume-based simulation continues. An overall schedule and control module is used to manage the pause of Eclipse reservoir simulation, the data transfer, the tracing of streamlines, the adjustment of well rates, and the continuation of the simulation. Figure 1 shows the combined streamline-based waterflood management and finite volume simulation workflow, with the four different modules involved.

The streamline tracing module implemented in this work uses the standard Pollock's tracing method [20], together with isoparametric mapping to conduct streamline tracing on general curvilinear structured grid, that is, corner point grid [21]. We use Eclipse's format and keywords for the input of corner point geometry. The module is also capable of handling nonneighboring faults in Eclipse's general corner point grid geometry with nonneighbor connections, which uses the tracing algorithms proposed in the previous work [22]. Figure 2 demonstrates streamlines traced through neighboring and nonneighboring faults. When tracing streamlines in an incompressible velocity field where the divergence of the velocity field equals zero everywhere, streamlines may either start at an injector and end at a producer, or form a loop. When tracing in a compressible velocity field, we have one more possibility that the streamlines may end or start in the middle of the reservoir due to compressibility. The different possible outcomes of streamline tracing in incompressible and compressible velocity fields are shown in Figure 3. Our streamline tracing module is able to deal with all these different tracing scenarios for Eclipse's general field scale simulation models. Data transfer from Eclipse to the streamline tracing module, such as the multiphase velocity field, are performed through reading Eclipse's restart files, by activating certain keywords in Eclipse's input file.

Interwell fluxes derived from streamlines give a snapshot of the connectivity between injectors and producers in the reservoir. Streamlines serve as pathways for fluid to travel through the reservoir, if the velocity field was held as steady state. We assume each streamline carries certain multiphase fluxes from one end to the other. Summation of fluxes for all the streamlines connecting a certain injector and a producer is performed to calculate the interwell multiphase fluxes between these two wells. When calculating these fluxes, we only consider the standard scenario that a streamline starts at a perforation grid block of an injector and ends at a perforation block of a producer. Figure 4 shows the method for interwell flux calculations. For all the streamlines started from the same face of a perforation grid block of an injector, they would carry the same amount of flux. The summation of all the fluxes carried by all these streamlines would be equal to the total amount of flux flowing out of that face of the perforation grid block, which could be easily 
4. Overall schedule and control; data transfer

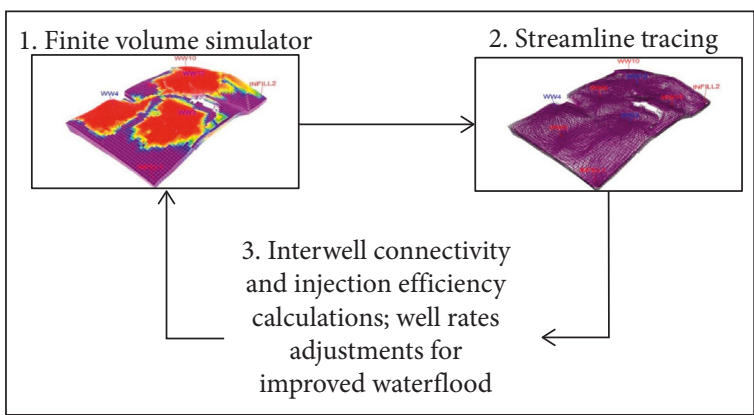

FIGURE 1: Combined streamline-based waterflood management and finite volume simulation workflow, with the four different modules involved.

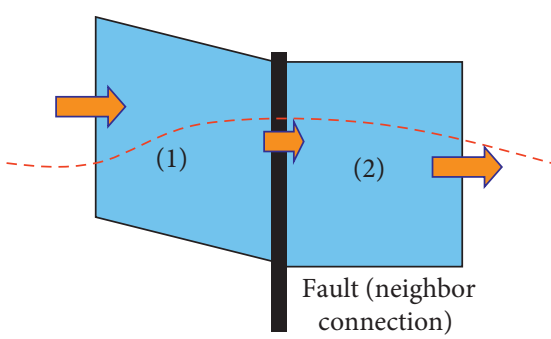

(a)

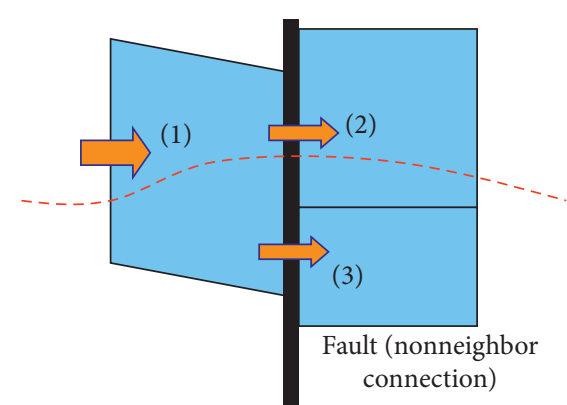

(b)

FIGURE 2: Streamline tracing through neighboring (a) and nonneighboring (b) faults in corner point grid system.

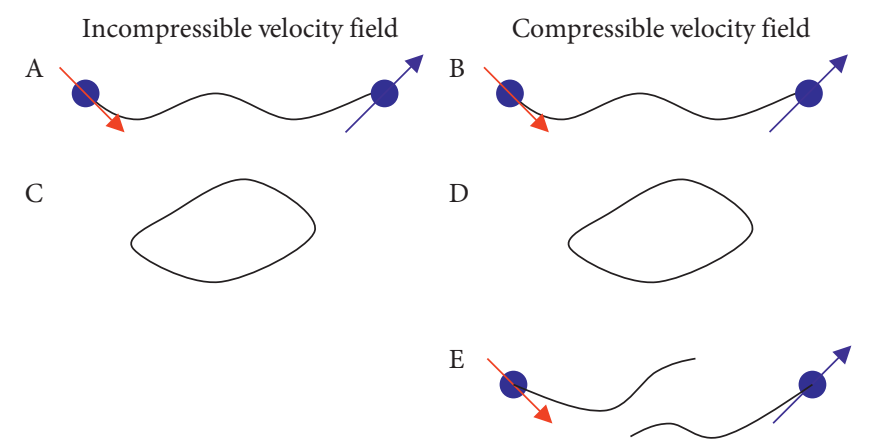

(a)

(b)

Figure 3: Possible outcomes of streamline tracing in incompressible (a) and compressible (b) velocity fields: (A, B) starting from an injector and ending in a producer; (C, D) forming a loop; (E) ending/starting in the middle of the reservoir due to compressibility.

derived from the finite volume simulation results. Since the streamlines start or end at faces of the perforation grid blocks, this streamline tracing module is able to handle any general shape of wells: vertical or horizontal wells, continuous or discontinuous perforations.

After obtaining the interwell fluxes by streamline tracing, we may further calculate the well allocation factor (WAF) and each injector's injection efficiency (IE) for the purpose of further well rate adjustments for improved waterflood performance [15-17]. The WAF for an injector is defined as the amount of flux going from an injector to a producer, divided by the total flux going from that injector to all producers, and vice versa for WAF for a producer. The IE for an injector is total offset oil production supported by this injector divided by water injection [15]. It equals for every unit volume of water injected into an injector and how much volume of oil is produced at the connected offset producers at that instant in time. Figure 5 demonstrates the example of IE calculation for an injector, with pressure support and streamlines connected to 4 other producers.

After IEs for all the injectors are calculated, reallocation of water injection can be conducted to direct more water to such injectors with higher injection efficiencies, so that in the following simulation period more oil could be produced and less water will be cycled between the injector-producer pairs. We implement the similar empirical analytical equations to 


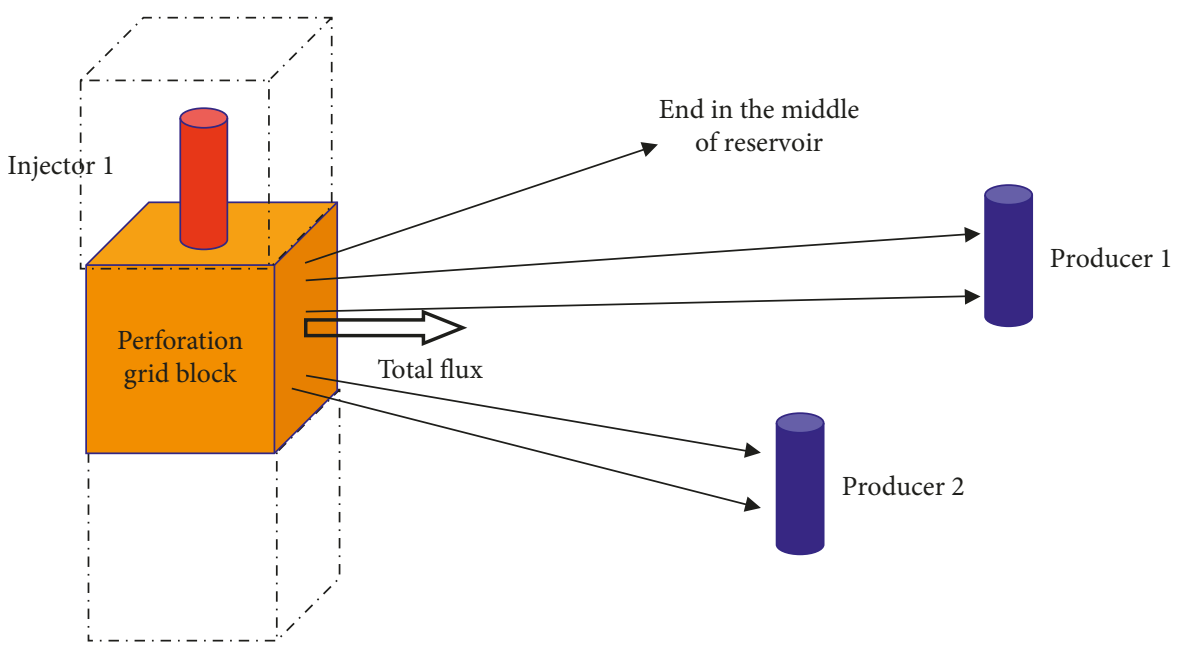

FIGURE 4: Interwell flux calculations: summation of multiphase fluxes for all the streamlines connecting a certain injector and a producer, while assuming each streamline carries certain multiphase fluxes.

calculate the new weights for injection rate allocation from the water source, given by,

$$
\begin{aligned}
& e_{i}>\bar{e}: f_{i}=1+f_{\max }\left(\frac{\operatorname{MIN}\left(e_{i}, e_{\max }\right)-\bar{e}}{e_{\max }-\bar{e}}\right)^{\alpha}, \\
& e_{i}<\bar{e}: f_{i}=1+f_{\min }\left(\frac{\operatorname{MAX}\left(e_{i}, e_{\min }\right)-\bar{e}}{e_{\min }-\bar{e}}\right)^{\alpha},
\end{aligned}
$$

where $\bar{e}$ is the field average injection efficiency, $e_{i}$ is the injection efficiency for the $i$-th injector, $f_{i}$ is the injection allocation weight, $e_{\max }$ is injection efficiency upper limit for injection allocation for all the injectors, $e_{\min }$ is the injection efficiency lower limit for injection allocation for all the injectors, $\alpha$ is a constant, $f_{\text {max }}$ and $f_{\text {min }}$ are the maximum and minimum allocation weight at $e_{\max }$ and $e_{\min }$ injection efficiencies. Figure 6 demonstrates such reallocation of injection rate according to each well's injection efficiency to achieve improved flood efficiency, with $f_{i}$ being the weight for injection allocation.

As mentioned, the water injection reallocation scheme implemented above is empirical. The best choice of injection allocation control parameters $e_{\max }, e_{\min }, f_{\max }, f_{\min }$, and $\alpha$ should be decided on a case by case basis. Using improper parameters in the waterflood management practice may lead to less weakened waterflood performance improvements in reducing water cycling between injector-producer well pairs. Details of the discussions on these control parameters are presented in the previous work $[15,16]$.

\section{Result}

In this chapter, we demonstrate the actual performance of our streamline-based waterflood management software package and reservoir recovery case studies using such tool.

We start with a simple test example to show our software package's capability of streamline tracing through the most difficult nonneighbor connection faults in a reservoir simulation model [22]. Figure 7 shows the streamlines traced in

\begin{tabular}{lcccc}
\multicolumn{5}{c}{ Injection efficiency calculation example } \\
\hline $\begin{array}{c}\text { I5/P3 } \\
\text { pair }\end{array}$ & $\begin{array}{c}\text { I5/P4 } \\
\text { pair }\end{array}$ & $\begin{array}{c}\text { I5/P5 } \\
\text { pair }\end{array}$ & $\begin{array}{r}\text { I5/P7 } \\
\text { pair }\end{array}$ \\
\hline $\begin{array}{l}\text { Oil production for } \\
\text { injector-producer } \\
\text { well pairs }\end{array}$ & 100 & 200 & 300 & 400 \\
\hline & & & \\
\hline I5 injection rate & I5's injection efficiency (IE) \\
\hline 2000 & $(100+200+300+400) / 2000=50 \%$
\end{tabular}

FIGURE 5: Example of injection efficiency calculation for injector I5, with pressure support and streamlines connecting to producer P3, P4, P5, P7.

such test problem. We consider single-phase incompressible steady-state fluid flow in a close to rectangular-shaped reservoir with a major fault in the middle. One injector and one producer are introduced in the two corners of the reservoir with constant bottom hole pressure controls. Through the side view, we clearly see the nonneighbor connections across the fault. Our streamline tracing module has the full capability to track streamline exits on one side of the fault and to find streamline entries on the other side of that fault, which forms smooth transitions for such streamline trajectories across the fault.

We further show a realistic case study for a heavily faulted reservoir under waterflood with multiple well pairs using our streamline-based waterflood management software. This case study consists of a two-phase (oil and water) waterflood simulation problem in Eclipse. The simulation grid, which is general corner point grid defined by Eclipse' COORD and ZCORN keywords, has the dimension of $20 \times$ $29 \times 12$. Figure 8 shows oil formation volume factor and viscosity at different pressures for the tested waterflood problem. Table 1 gives the water properties in this simulation case. Water-oil relative permeability curves are shown in Figure 9. The solution gas-oil ratio value Rs is set as constant 


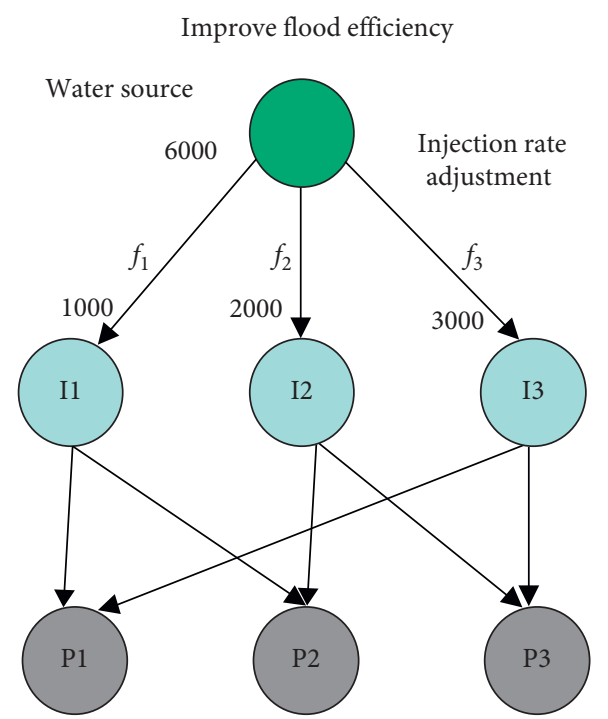

FIGURE 6: Demonstration of streamline-based waterflood management: reallocation of injection rate according to each well's injection efficiency to achieve improved flood efficiency.
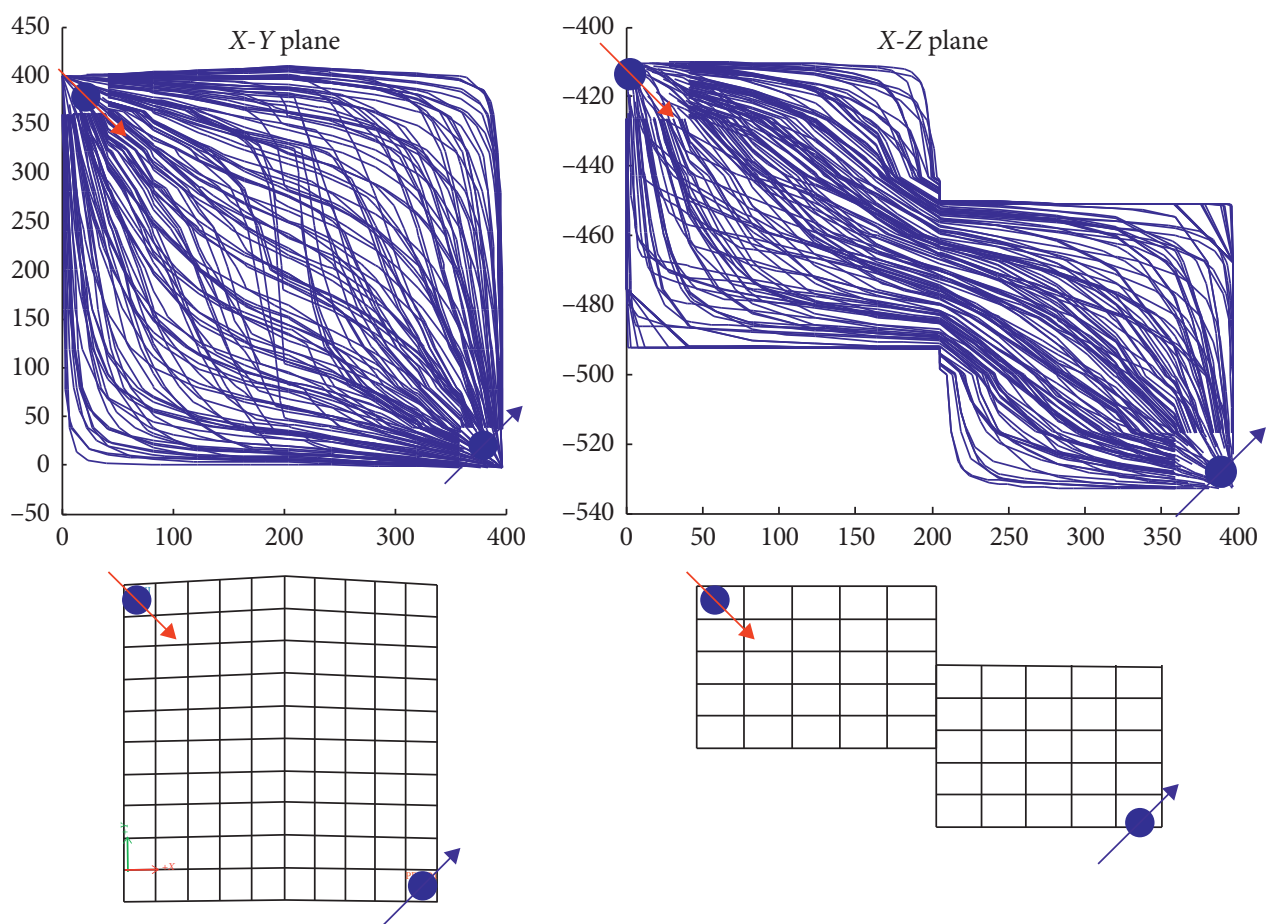

Figure 7: Streamline tracing test problem: single-phase incompressible steady-state fluid flow and simple reservoir with nonneighbor connection fault.

of $0.8686 \mathrm{Mscf} / \mathrm{stb}$. The rock compressibility is $8.10 \mathrm{E}-61 / \mathrm{psi}$, with reference pressure of 5,000 psi.

Figure 10 shows the porosity distribution in this finite volume-based reservoir simulation model with $z$-axis exaggerated. The permeability distribution is shown in Figure 11, also with the $z$-axis exaggerated. Figure 12, which is the structural side view of the reservoir, shows all the geologic faults. The reservoir is initially equilibrated at $5,560 \mathrm{ft}$ datum depth, with 5,000 psi datum pressure. The oilwater contact is set to be $6,755 \mathrm{ft}$ deep. Figure 13 further demonstrates the depth of each grid block in the simulation model.

This reservoir has 4 water injectors and 12 oil producers. The injectors are on initial rate controls of 22,500 rb/day (adjustable in later stage of the simulation for streamlinebased waterflood management). The field total water injection rate is $90,000 \mathrm{rb} /$ day correspondingly. The producers are on reservoir fluid volume rate control at $7,500 \mathrm{rb} /$ day. This gives reservoir voidage replacement ratio of 1 , without significant pressure depletion of the reservoir. The 


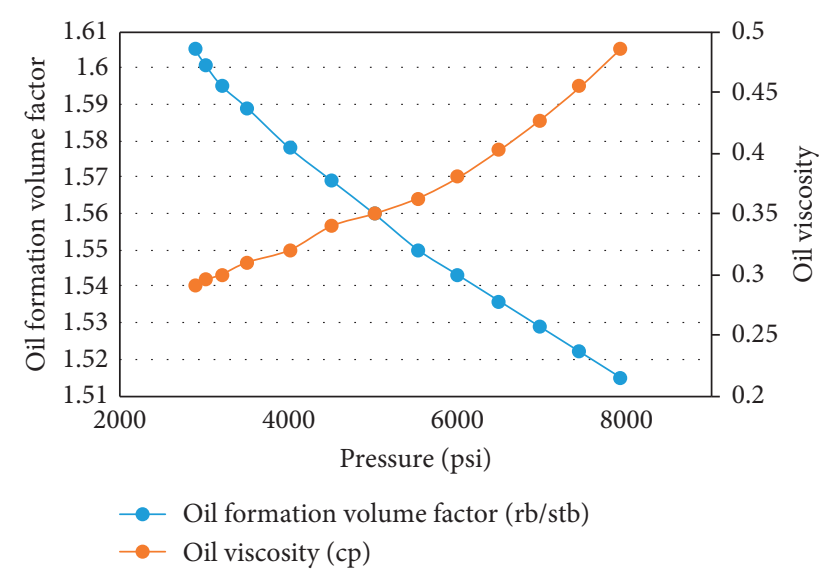

FIgURE 8: Oil formation volume factor and viscosity at different pressures for the heavily faulted reservoir case.

TABle 1: Water properties for the heavily faulted reservoir case.

\begin{tabular}{lccc}
\hline $\begin{array}{l}\text { Reference } \\
\text { pressure } \\
(\mathrm{psi})\end{array}$ & $\begin{array}{c}\text { Water formation } \\
\text { volume factor } \\
\text { at reference } \\
\text { pressure }(\mathrm{rb} / \mathrm{stb})\end{array}$ & $\begin{array}{c}\text { Water } \\
\text { compressibility } \\
(1 / \mathrm{psi})\end{array}$ & $\begin{array}{c}\text { Water } \\
\text { viscosity at } \\
\text { reference } \\
\text { pressure }(\mathrm{cp})\end{array}$ \\
\hline 5,000 & 1.04 & $3.3 e-006$ & 0.31 \\
\hline
\end{tabular}

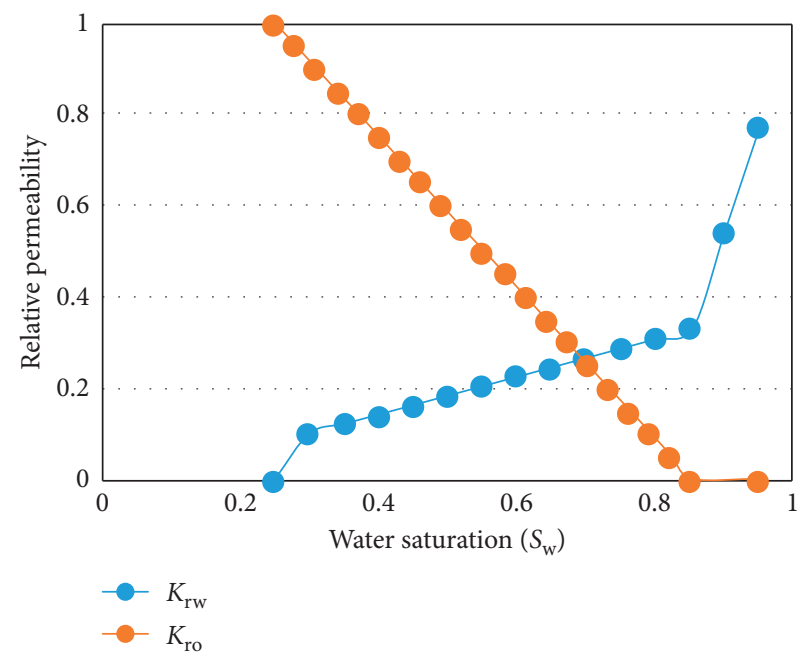

FIGURE 9: Water-oil relative permeability curves for the heavily faulted reservoir case.

maximum and minimum bottom hole pressures for injectors and producers are set to be 20,000 psi and $450 \mathrm{psi}$, respectively.

We start with normal reservoir simulation without any streamline tracing and rate adjustments. Waterflood is continued for 15 years for this reservoir. Figure 14 shows the oil saturation distribution of the reservoir at the end of 15 years. As seen, large area of the reservoir has been swept by water, which we expect high water cut in certain producers. The waterflood sweep efficiency, however, is not very high, leaving large amount of unswept oil behind. This case serves

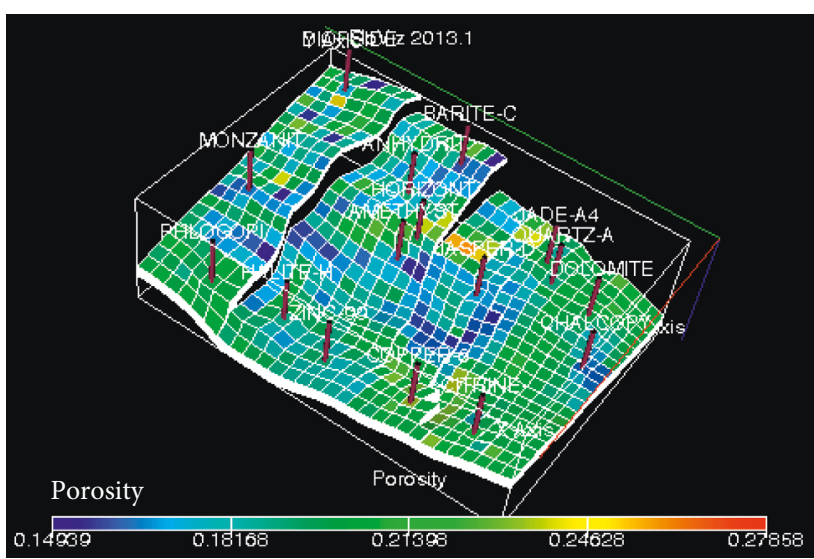

FIGURE 10: Porosity distribution for the heavily faulted reservoir case ( $z$-axis exaggerated).

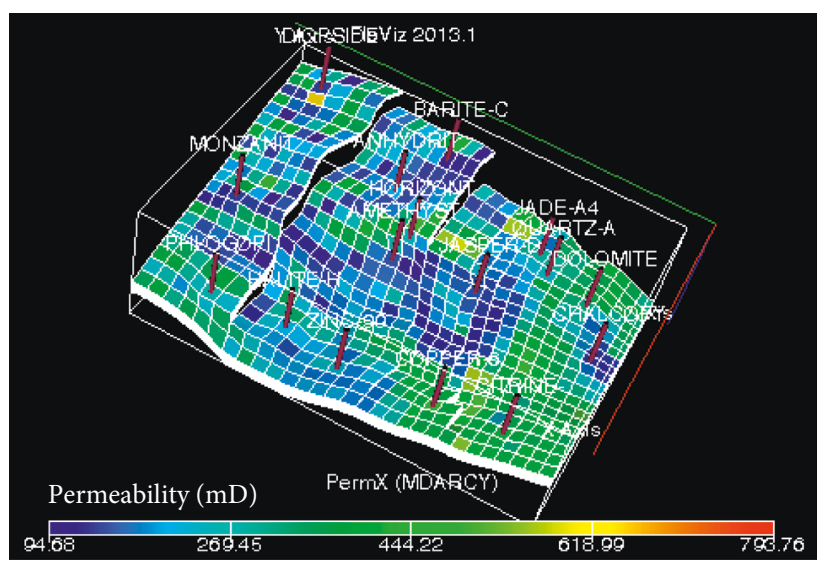

FIgure 11: Permeability distribution for the heavily faulted reservoir case ( $z$-axis exaggerated).

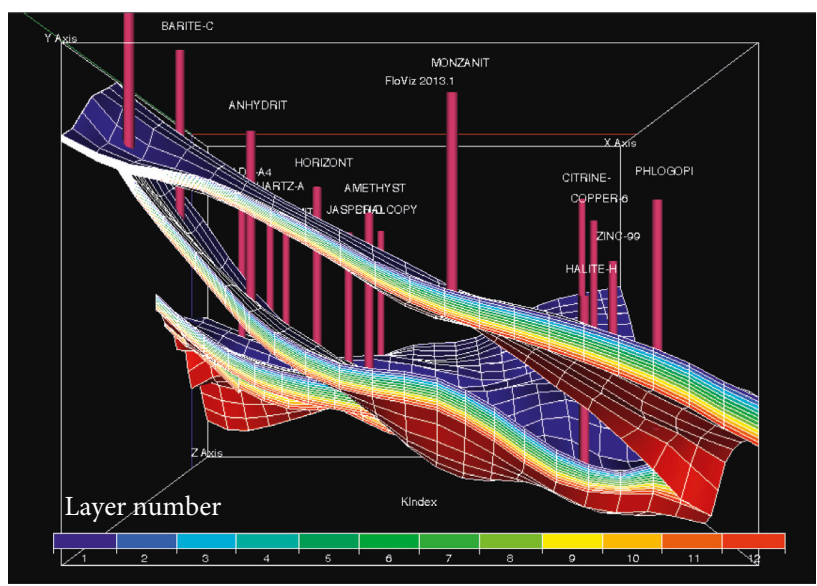

FIgURE 12: Structural side view of the reservoir for the heavily faulted reservoir case, showing all the geologic faults ( $z$-axis exaggerated).

as an ideal candidate for implementing the streamline-based waterflood adjustments.

In the next stage, we conduct waterflood management using interwell flux information from streamline tracing. We 


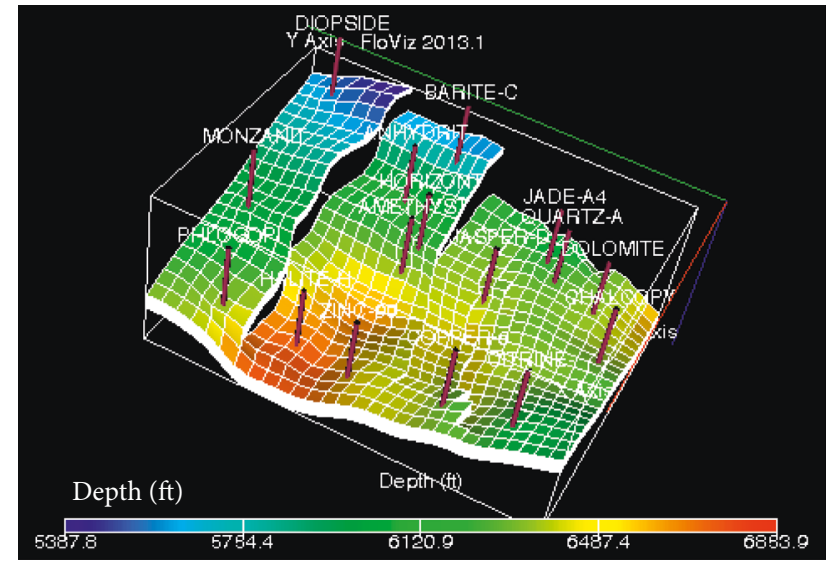

FIGURE 13: Depth of each grid block in the simulation model for the heavily faulted reservoir case ( $z$-axis exaggerated).

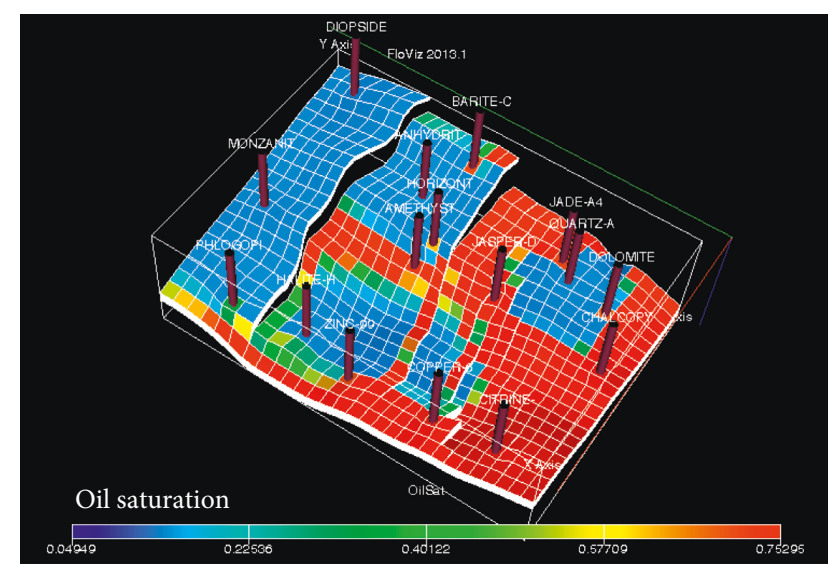

Figure 14: Oil saturation of the reservoir at the end of 15 years for the heavily faulted reservoir case ( $z$-axis exaggerated).

divide the entire 15 years simulation time span into several periods. In each period, Eclipse reservoir simulation is continued for 3 years, before the simulation is paused for streamline tracing. Streamlines are traced on total-phase velocity field (summation of oil, water and gas phase velocities) outputted from Eclipse as suggested in previous literatures [1]. Interwell fluxes are calculated through the tracing, which further yields waterflood efficiency metrics such as WAF and IE. We assume the total field water injection rate is held constant at 90,000 stb/day, that is, injection from a certain water source. The producers are still on reservoir fluid volume rate control of 7,500 rb/day. Using the previous empirical allocation weight Equations (1) and (2), we determine the new water injection rate for each injector in the next 3-year period. Then, we move into the next period, with Eclipse simulation continued for another 3 years with the adjusted injection rates. Such iterative process continues until we reach the end of 15 years. Note the total simulation time and the period length between adjacent streamline tracing operations are all adjustable in our program, when dealing with all the simulation cases.

Figure 15 shows the streamlines traced using the streamline tracing program at the end of 15 years, with $x, y$, and $z$ axis being each cell's $\mathrm{I}$, $\mathrm{J}$, and $\mathrm{K}$ index. As seen, our program has the full capability of tracing streamlines based on the total-phase velocity field outputted from Eclipse on this heavily faulted reservoir. The streamlines give a graphical representation of such a snapshot of the reservoir fluid flow field. It also serves as a diagnostic tool to identify connectivity between injector and producer well pairs, that is, whether an injector is connected or disconnected with another producer if the velocity field was held constant for a certain period of time. Coupled with $3 \mathrm{D}$ visualization technology, streamlines provide such vivid tool for reservoir engineers to make analysis and interpretations.

Assuming each streamline carries certain multiphase fluxes, the interwell fluxes are derived. Table 2 is the interwell total-phase fluxes calculated for the injector-producer well pairs at the end of 3 years. If the velocity field does not change significantly over time, that is, close to quasi-steadystate conditions, which is valid for most reservoir recovery processes, interwell fluxes from streamline tracing would yield very similar values of well allocation factors as the ones calculated using the tracer option in reservoir simulation [19]. Table 3 further shows the injection efficiencies calculated for all the injectors at the end of 3 years. We see some differences in IE for different injectors from the early stage of waterflood due to reservoir heterogeneity and corresponding uneven sweep. More water will be diverted to the injectors with higher injection efficiency in the next stage of simulation.

With such "simulate-pause/trace/adjust-simulate" methodology implemented in our case study and using the empirical equations described earlier for determining water injection rates in the next simulation period (Equations (1) and (2)), we show the improved oil recovery achieved in this case by using streamline-based waterflood management. Figure 16 shows the improved oil recovery for this reservoir model, with comparisons of using and not using streamlinebased flood management. After 3 consecutive streamline tracing and injection adjustment operations, the field oil production rate increases by $6.9 \%$ at the end of 12 year, when comparing with the case of "do nothing." The adjustments have reduced water cycling between inefficient injectorproducer well pairs. More oil has been swept by the same single source of injection water by conducting the injection rate reallocations based on IEs. Furthermore, comparison of entire field production performance at end of 12 years for the cases with and without streamline-based flood management is shown in Table 4 . The oil cut has increased from $23.1 \%$ to $25.0 \%$, with field oil production rate increased from $17,910 \mathrm{stb} /$ day to $19,200 \mathrm{stb} /$ day, an increase of $7.2 \%$. Water production rate has decreased from $59,651 \mathrm{stb} /$ day to $57,700 \mathrm{stb} /$ day, a decrease of $3.3 \%$.

Finally, we further show another case for peripheral water drive using our streamline-based waterflood management methodology. This case study is three phase (oil, gas, and water) waterflood problem in Eclipse. Again, we define the general corner point grid in the Eclipse simulation with the dimension of $50 \times 50 \times 6$. Figure 17 shows the permeability distribution in this finite volume-based reservoir simulation model. The porosity distribution is shown 


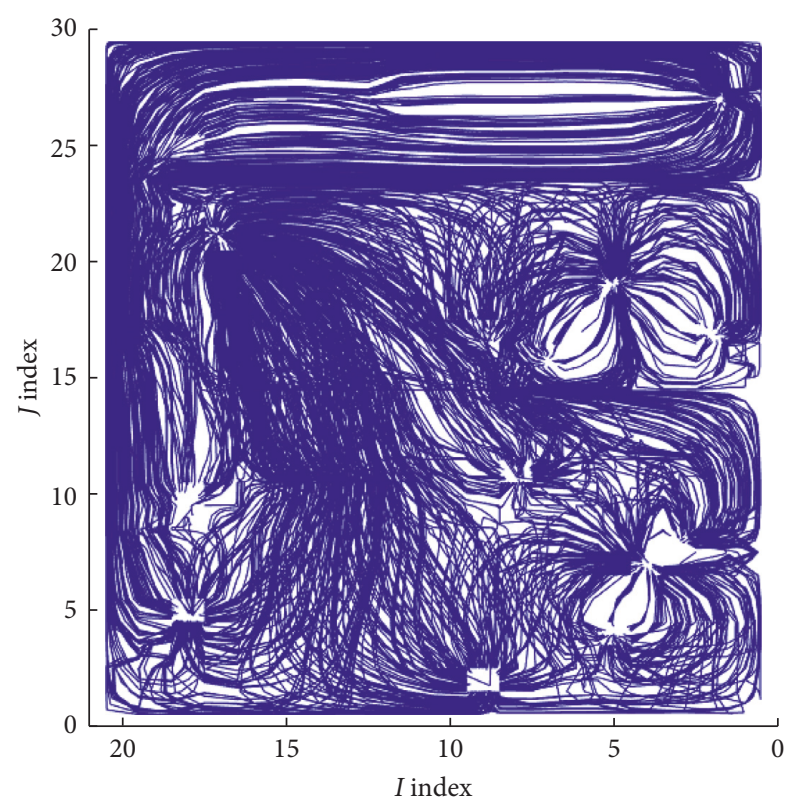

FIGURE 15: Streamlines traced using the streamline tracing program at the end of 15 years for the heavily faulted reservoir case, with $x, y$, and $z$ axis being each cell's $\mathrm{I}$, J, and $\mathrm{K}$ index.

TABLE 2: Interwell total-phase fluxes calculated for the injector-producer well pairs at the end of 3 years for the heavily faulted reservoir case.

\begin{tabular}{|c|c|c|c|c|c|c|}
\hline Interwell total phase fluxes & P1 (rb/day) & P2 (rb/day) & P3 (rb/day) & P4 (rb/day) & P5 (rb/day) & $\ldots$ \\
\hline I1 & 5,213 & 4,001 & 529 & 3,088 & 0 & \\
\hline $\mathrm{I} 2$ & 0 & 3,801 & 0 & 0 & 0 & $\ldots$ \\
\hline $\mathrm{I} 3$ & 2,987 & 840 & 595 & 1,203 & 6,455 & \\
\hline I4 & 0 & 3,510 & 5,351 & 0 & 0 & \\
\hline
\end{tabular}

TABLE 3: Injection efficiencies (IEs) for all the injectors at the end of 3 years for the heavily faulted reservoir case.

\begin{tabular}{lcccc}
\hline Injector name & I1 & I2 & I3 & I4 \\
\hline Injection efficiency (\%) & 71.2 & 47.9 & 70.4 & 52.2 \\
\hline
\end{tabular}

in Figure 18. We can see the geologic faults in these figures. This peripheral water drive reservoir has 4 water injectors and 6 oil producers. The injectors are on initial rate controls of $300,000 \mathrm{rm}^{3} /$ day (adjustable in later stage of the simulation for streamline-based waterflood management). The producers are on reservoir fluid volume rate control, with the vertical producers operating at $50,000 \mathrm{rm}^{3} /$ day and the horizontal producers at $500,000 \mathrm{rm}^{3} /$ day. Again, the reservoir voidage replacement ratio is 1, without pressure depletion.

We first conduct finite volume reservoir simulation without streamline tracing and flood management. Figure 19 shows the oil saturation distribution of the reservoir at the end of 30 years. Large area of the reservoir has been invaded by water after 30 years. Streamline-based waterflood management can be used in the next stage to improve the flood efficiency. We divide the entire 30 years simulation time span into 10 separate periods. In each period, we run Eclipse reservoir simulation first, before we pause the simulation, trace the streamlines, adjust the injection rate for each individual well, and continue into the next period. Again, we trace the total- phase velocity field outputted from Eclipse. We obtain the interwell fluxes and waterflood efficiency indicators (WAF and IE). We further conduct the waterflood adjustment using the interwell flux information from streamline tracing. We assume a constant total field water injection rate of 1,200,000 $\mathrm{rm}^{3} /$ day. The well controls for producers are still the same, $50,000 \mathrm{rm}^{3} /$ day for vertical producers and $500,000 \mathrm{rm}^{3} /$ day for horizontal producers. Using the water injection allocation Equations (1) and (2), we determine the new water injection rate for each injector in the next period. Eclipse reservoir simulation is then continued into the next period.

Figure 20 shows the streamlines traced at the end of 30 years, with $x, y$, and $z$ axis being each cell's $\mathrm{I}$, J, and $\mathrm{K}$ index. Our program has the capability of tracing streamlines for this three-phase peripheral water drive problem. The streamline is a diagnostic tool to identify connectivity between injector and producer well pairs. Table 5 shows the interwell total-phase fluxes calculated for the well pairs at the end of 30 years. Table 6 further shows the injection efficiencies calculated for all the injectors at the end of 30 years. We see clear difference in IE values for different injectors, showing different flood efficiencies. We divert more water to the injectors with higher injection efficiency in the process.

Eventually, we show the improved oil recovery achieved in this peripheral water drive case in Figure 21, by comparing the results obtained with and without streamline-based flood 


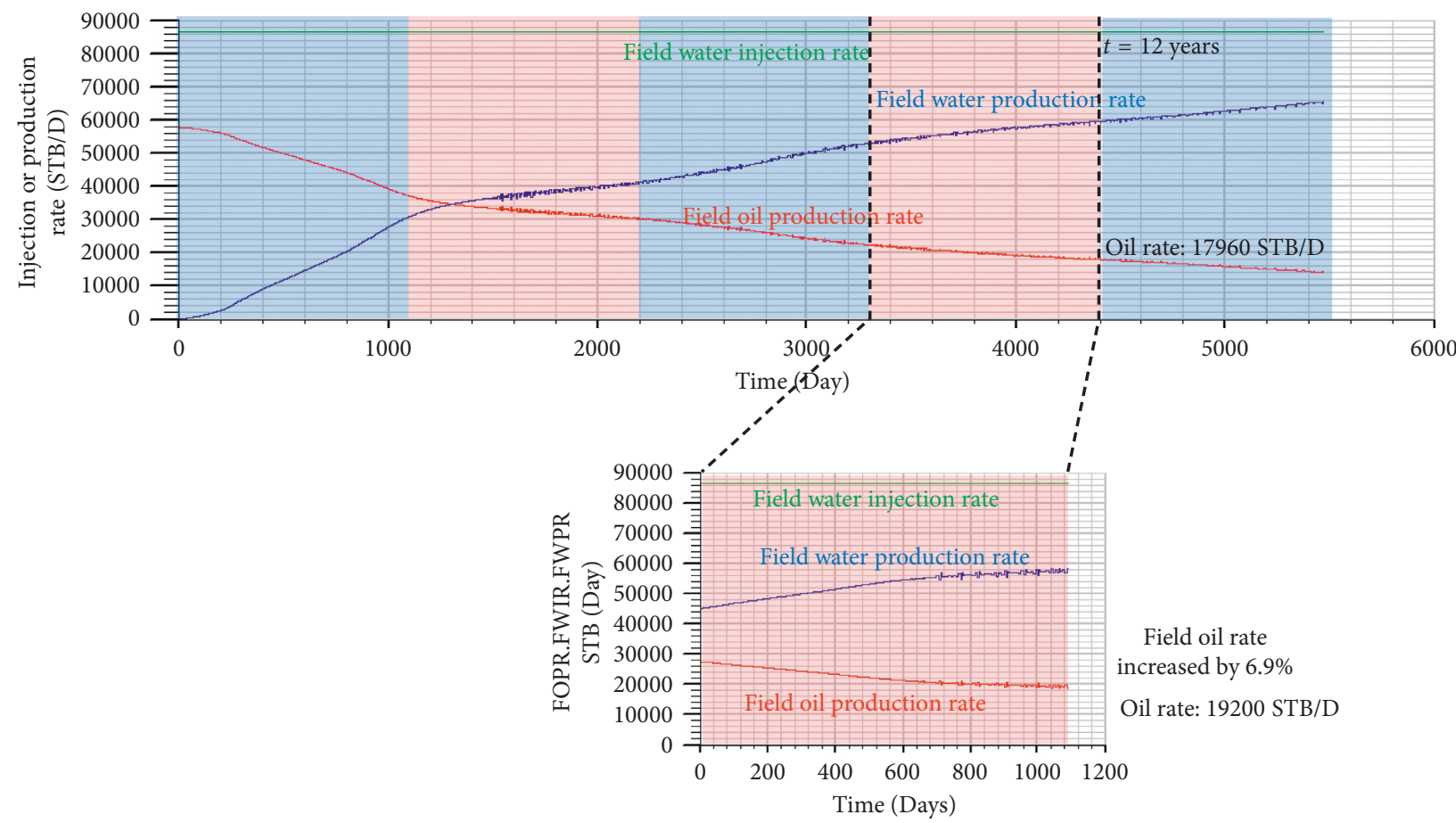

FIGURE 16: Improved oil recovery for the heavily faulted reservoir case by using streamline-based flood management: field oil production rate increase by $6.9 \%$ at the end of 12 year.

TABLE 4: Comparisons of entire field production performance at end of 12 years with and without streamline-based flood management for the heavily faulted reservoir case.

\begin{tabular}{|c|c|c|c|c|}
\hline $\begin{array}{l}\text { Comparisons of entire field } \\
\text { production performance at end of } 12 \text { years }\end{array}$ & $\begin{array}{c}\text { Field water } \\
\text { injection rate (stb/day) }\end{array}$ & $\begin{array}{l}\text { Field oil } \\
\text { production rate }(\mathrm{stb} / \mathrm{day})\end{array}$ & $\begin{array}{l}\text { Field water } \\
\text { production } \\
\text { rate (stb/day) }\end{array}$ & Oil cut $(\%)$ \\
\hline Without streamline-based flood management & 86,559 & 17,960 & 59,651 & 23.1 \\
\hline With streamline-based flood management & 86,559 & 19,200 & 57,700 & 25.0 \\
\hline
\end{tabular}

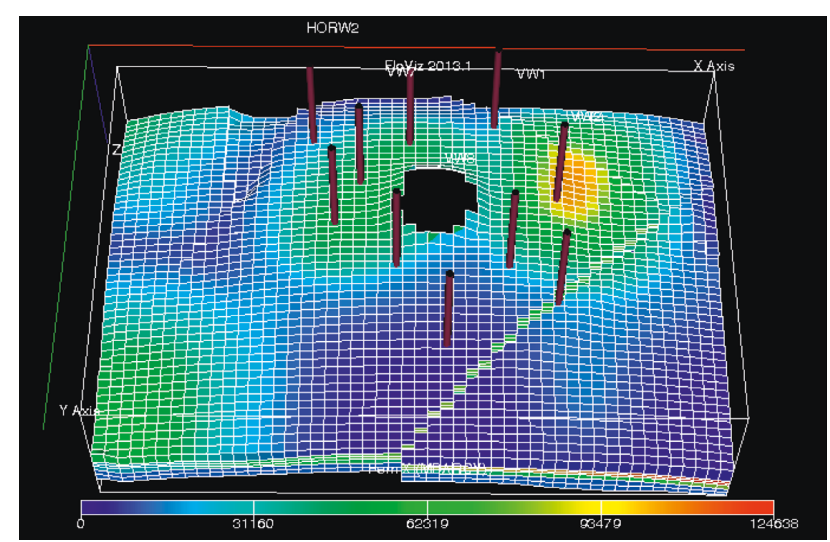

FIGURE 17: Reservoir permeability distribution for the peripheral water drive case ( $z$-axis exaggerated).

management. After 15 years, the field water cut decreases from $24.4 \%$ to $22.8 \%$, when comparing with the case of "do nothing." After 27 years, the total field water cut decreases from $44.7 \%$ down to $43.1 \%$. We have successfully mitigated high water cut production between inefficient injector-

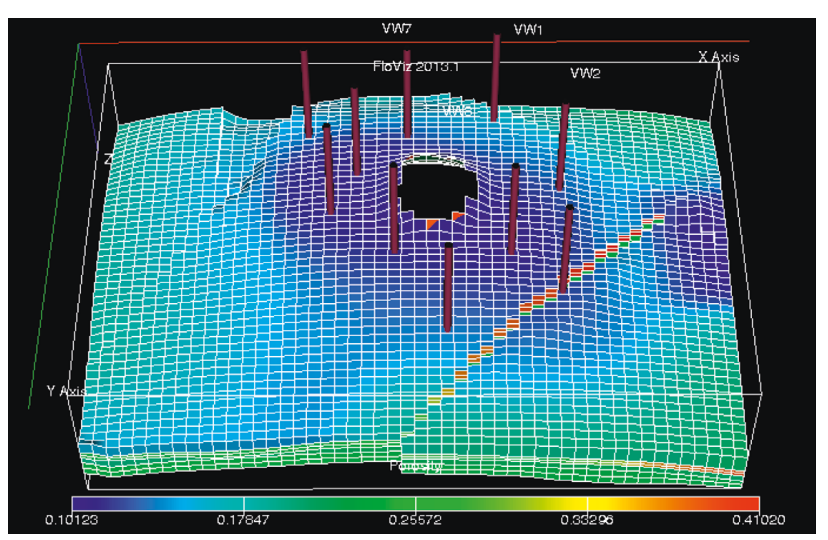

FIGURE 18: Reservoir porosity distribution for the peripheral water drive case ( $z$-axis exaggerated).

producer well pairs. Furthermore, Table 7 shows the water cut for each individual well with and without streamlinebased flood management for the peripheral water drive case. We achieve water cut reduction in most of the producers after 15 and 27 years. 


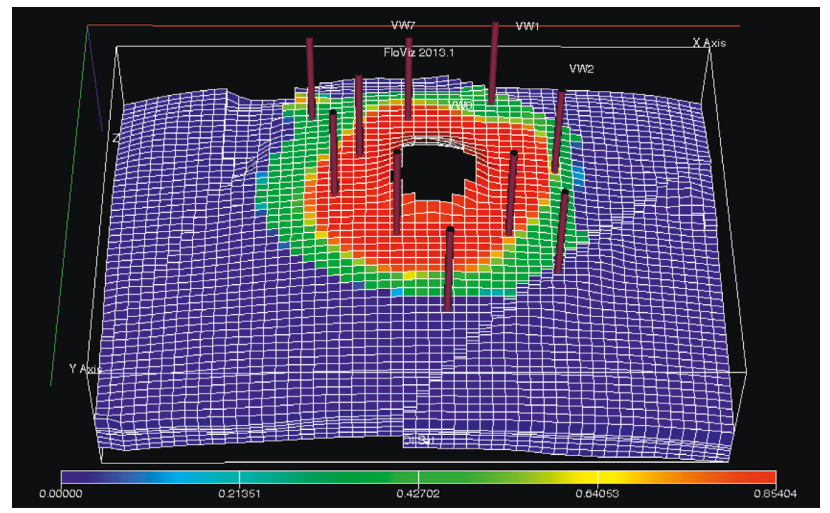

FIGURE 19: Oil saturation distribution after 30 years for the peripheral water drive case ( $z$-axis exaggerated).

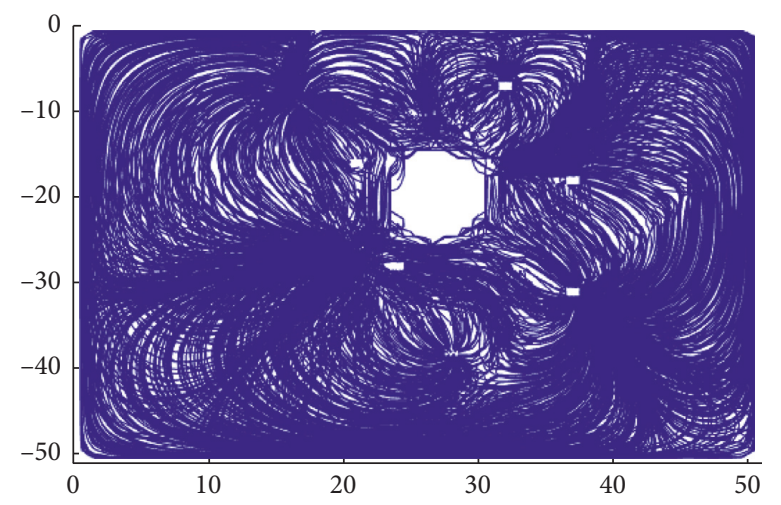

FIGURE 20: Streamlines traced using the streamline tracing program at the end of 30 years for the peripheral waterflood case, with $x, y$, and $z$ axis being each cell's I, J, and $\mathrm{K}$ index.

TABLE 5: Interwell three-phase total fluxes after 30 years for the peripheral water drive case.

\begin{tabular}{lcccc}
\hline & $\begin{array}{c}\text { VW8 } \\
\left(\mathrm{rm}^{3} / \mathrm{d}\right)\end{array}$ & $\begin{array}{c}\text { VW4 } \\
\left(\mathrm{rm}^{3} / \mathrm{d}\right)\end{array}$ & $\begin{array}{c}\mathrm{VW5} \\
\left(\mathrm{rm}^{3} / \mathrm{d}\right)\end{array}$ & $\begin{array}{c}\mathrm{VW} 2 \\
\left(\mathrm{rm}^{3} / \mathrm{d}\right)\end{array}$ \\
\hline VW1 & 0 & 0 & 0 & 39,466 \\
VW3 & 0 & 27,354 & 0 & 0 \\
VW6 & 0 & 4,634 & 24,077 & 23,637 \\
VW7 & 3,444 & 12,305 & 0 & 34,236 \\
HORW1 & 0 & 187,860 & 182,611 & 103,665 \\
HORW2 & 49,747 & 339,349 & 0 & 92,178 \\
\hline
\end{tabular}

TABLE 6: Injection efficiency for each injector after 30 years for the peripheral water drive case.

\begin{tabular}{lcccc}
\hline & VW8 & VW4 & VW5 & VW2 \\
\hline Injection efficiency (\%) & 6.2 & 66.8 & 39.8 & 68.0 \\
\hline
\end{tabular}

Overall, our method has achieved such economical benefit without any additional costly measures. The only changes made here are dynamically determined injection rates according to streamline-based interwell flux information. Such method brings great economic benefits for brown field oil producers in post breakthrough waterflood reservoir developments, since by doing so almost no investments are needed to have some increase in their oil production rate (typically on the order of around $5-10 \%$ as compared with "do nothing" in most cases that we have tested). Note in all the work conducted here, rigorous finite volume-based reservoir simulation is used for production forecast, fully capturing the nonadvective physics such as gravity segregations and capillary effects. Our streamline tracing and waterflood management program has worked cooperatively with the commercial finite volume reservoir simulator Eclipse.

\section{Summary}

In conclusion, we have implemented a novel streamlinebased waterflood management software program to improve oil recovery. We achieve the following conclusions.

(1) The software combines the advantages of commercial reservoir simulator with the functionality of streamline tracing and corresponding waterflood improvements.

(2) As compared with previous approaches based on streamline simulations, we stay with the classical general purpose finite volume-based simulations to ensure wider applicable ranges, rigorous nature of such simulations, and minimal changes to existing original simulation cases. 


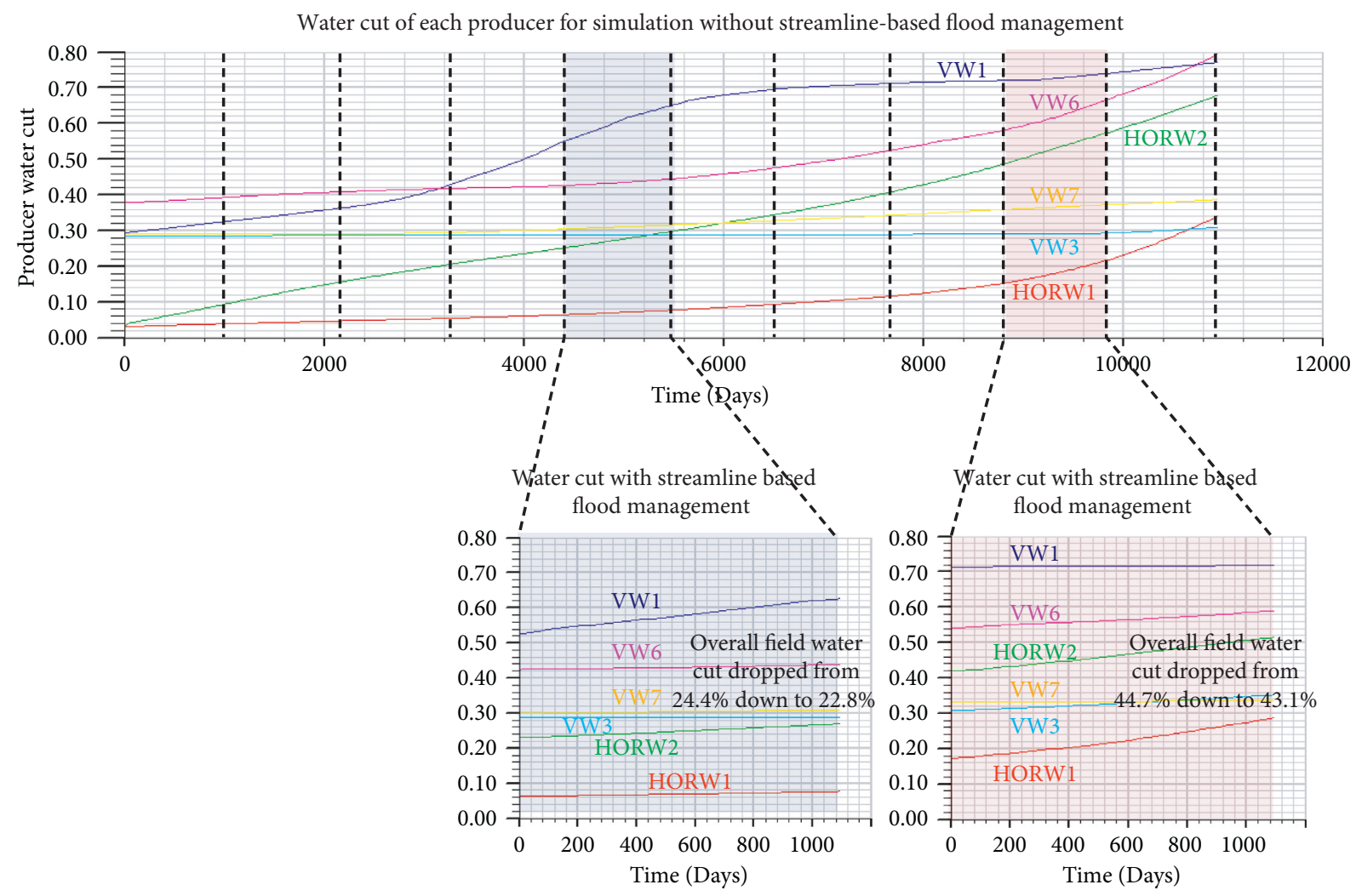

FIGURE 21: Improved oil recovery for the peripheral water drive case by using streamline-based flood management.

TABLE 7: Water cut for individual wells with and without streamline-based flood management for the peripheral water drive case.

\begin{tabular}{lcccc}
\hline Well name & $\begin{array}{c}\text { Without flood } \\
\text { management } \\
\text { (end of 15 years) }\end{array}$ & $\begin{array}{c}\text { With flood management } \\
\text { (end of 15 years) }(\%)\end{array}$ & $\begin{array}{c}\text { Without flood management } \\
\text { (end of 27 years) }(\%)\end{array}$ & $\begin{array}{c}\text { With flood management } \\
\text { (end of 27 years) }(\%)\end{array}$ \\
\hline VW1 & 65.1 & 62.7 & 74.1 & 71.8 \\
VW3 & 28.8 & 28.8 & 29.3 & 35.2 \\
VW6 & 44.5 & 43.9 & 66.9 & 59.0 \\
VW7 & 31.6 & 30.9 & 37.3 & 33.5 \\
HORW1 & 7.7 & 7.7 & 21.8 & 28.7 \\
HORW2 & 29.7 & 26.9 & 57.5 & 51.4 \\
\hline
\end{tabular}

(3) After such waterflood adjustments, we observe typical reduction in reservoir water cut of up to $5 \%$. Interwell flux helps to diagnose and find well pairs with large amount of water cycling.

(4) The software serves an effectively method for reducing water cycling and increasing oil recovery in waterflood fields without conducting any other measures, that is, improved oil recovery (IOR), enhanced oil recovery (EOR), well stimulation treatments, etc.

\section{Data Availability}

The computer program source code and executable data used to support the findings of this study have not been made available because it is proprietary intellectual property of China University of Petroleum (Beijing) and PetroChina. The reservoir simulation setting data used to support the findings of this study are included within the article.

\section{Disclosure}

Part of this work was previously presented as conference proceeding in the 2018 Society of Petroleum Engineering Kingdom of Saudi Arabia Section (SPE-KSA) Annual Technical Symposium and Exhibition (ATS\&E), Apr 23-26, 2018. The authors thank PetroChina for their permission to present this paper.

\section{Conflicts of Interest}

The authors declare that they have no conflicts of interests.

\section{Acknowledgments}

This work was supported by the National Science and Technology Major Project of the Ministry of Science and Technology of China (2017ZX05013-002) Method and Key Technology of Enlarging Water Flooding Swept Volume for Low Permeability and Extra Low Permeability Reservoir and 
"CNPC major technology project 2016B-1302" Research on Flooding Control Technique and Dynamic Reservoir Simulation Method in Low Permeability and Extra Low Permeability Reservoir. It was also funded by the Science Foundation of China University of Petroleum, Beijing (No. 2462016YJRC016) and "CNPC major technology project 2016E-05" Key Technology Research and Application for Efficient Stable Annual Production of 50 Million Tons in Changqing Oil Field. The authors also want to thank Marco Thiele from Streamsim Inc. and Margot Gerritsen from Stanford University for insightful discussions on the streamline simulation technology. The authors thank Yan Peng from China University of Petroleum (Beijing) for his contributions in forming the main research ideas and also building the streamline visualization program. The authors thank Xiankang Xin from China University of Petroleum (Beijing) for building the reservoir simulation model, postprocessing the simulation data, and building the streamline program.

\section{References}

[1] R. P. Batycky, "A three-dimensional two-phase field scale streamline simulator," Ph.D. thesis, Stanford University, Stanford, CA, USA, 1997.

[2] I. Berre, H. K. Dahle, K. H. Karlsen, and H. F. Nordhaug, "A streamline front tracking method for two- and three-phase flow including capillary forces," Contemporary Mathematics, vol. 295, pp. 49-61, 2002.

[3] F. Bratvedt, T. Gimse, and C. Tegnander, "Streamline computations for porous media flow including gravity," Transport in Porous Media, vol. 25, no. 1, pp. 63-78, 1996.

[4] V. T. Beraldo, M. J. Blunt, and D. J. Schiozer, "Compressible streamline-based simulation with changes in oil composition," SPE Reservoir Evaluation and Engineering, vol. 12, no. 6, pp. 963-973, 2009.

[5] Z. Zhu, M. Thiele, and M. Gerritsen, "Thermal streamline simulation: steam floods," in Proceedings of SPE Reservoir Simulation Symposium, Woodlands, TX, USA, February 2011.

[6] Z. Zhu, "Efficient simulation of thermal enhanced oil recovery processes," Ph.D. thesis, Stanford University, Stanford, CA, USA, 2011.

[7] T. Clemens, J. Abdev, and M. R. Thiele, "Improved polymerflood management using streamlines," SPE Reservoir Evaluation and Engineering, vol. 14, no. 2, pp. 171-181, 2011.

[8] M. Thiele, R. P. Batycky, S. Pollitzer, and T. Clemens, "Polymer-flood modeling using streamlines," SPE Reservoir Evaluation and Engineering, vol. 13, no. 2, pp. 313-322, 2010.

[9] B. T. Mallison, "Streamline-based simulation of two-phase, multicomponent flow in porous media," Ph.D. thesis, Stanford University, Stanford, CA, USA, 2004.

[10] Z. Zhu, M. Gerritsen, and M. Thiele, "Thermal streamline simulation for hot waterflooding," SPE Reservoir Evaluation and Engineering, vol. 13, no. 3, pp. 372-382, 2010.

[11] P. Bastian, Z. Chen, R. E. Ewing, R. Helmig, H. Jakobs, and V. Reichenberger, "Numerical Simulation of Multiphase Flow in Fractured Porous Media," in Numerical Treatment of Multiphase Flows in Porous Media, pp. 52-70, Springer, Berlin, Heidelberg, Germany, 2000.

[12] Z. Chen, G. Huan, and Y. Ma, Computational Methods for Multiphase Flows in Porous Media, Computational Science and Engineering (Book 2), Society for Industrial and Applied Mathematics, Philadelphia, PA, USA, 2006.

[13] G. D. Donato, W. Huang, and M. J. Blunt, "Streamline-based dual porosity simulation of fractured reservoirs," in Proceedings of SPE Annual Technical Conference and Exhibition, Denver, CO, USA, October 2003.

[14] Z. Lei, B. Gong, F. Wang, T. Wang, and Q. Li, "A dynamic discrete fracture model for fluid flow in fractured lowpermeability reservoirs," in Proceedings of SPE Reservoir Characterisation and Simulation Conference and Exhibition, Abu Dhabi, UAE, September 2015.

[15] M. R. Thiele and R. P. Batycky, "Using streamline-derived injection efficiencies for improved waterflood management," SPE Reservoir Evaluation and Engineering, vol. 9, no. 2, pp. 187-196, 2006.

[16] M. R. Thiele and R. P. Batycky, "Water injection optimization using a streamline-based workflow," in Proceedings of SPE Annual Technical Conference and Exhibition, Denver, Colorado, USA, October 2003.

[17] R. P. Batycky and M. Thiele, "Technology update: mature flood surveillance using streamlines," Journal of Petroleum Technology, vol. 68, no. 5, pp. 22-25, 2016.

[18] J. Li, Z. Lei, S. Li et al., "Optimizing water flood performance to improve injector efficiency in fractured low-permeability reservoirs using streamline simulation," in Proceedings of SPE Kingdom of Saudi Arabia Annual Technical Symposium and Exhibition, pp. 25-28, Dammam, Saudi Arabia, April 2016.

[19] T. Wen, "Waterflood optimization using streamlines and reservoir management risk analysis with market uncertainty," Ph.D. thesis, Stanford University, Stanford, CA, USA, 2014.

[20] D. W. Pollock, "Semianalytical computation of path lines for finite-difference models," Ground Water, vol. 26, no. 6, pp. 743-750, 1988.

[21] M. Prevost, M. G. Edwards, and M. J. Blunt, "Streamline tracing on curvilinear structured and unstructured grids," SPE Journal, vol. 7, no. 2, pp. 139-148, 2002.

[22] E. A. Jimenez, A. Datta-Gupta, and M. J. King, "Full-field streamline tracing in complex faulted systems with nonneighbor connections," SPE Journal, vol. 15, no. 1, pp. 717, 2010. 


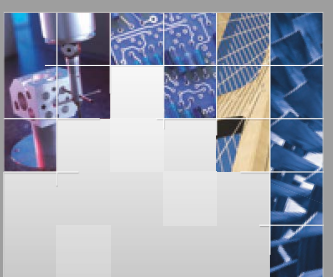

\section{Enfincering}
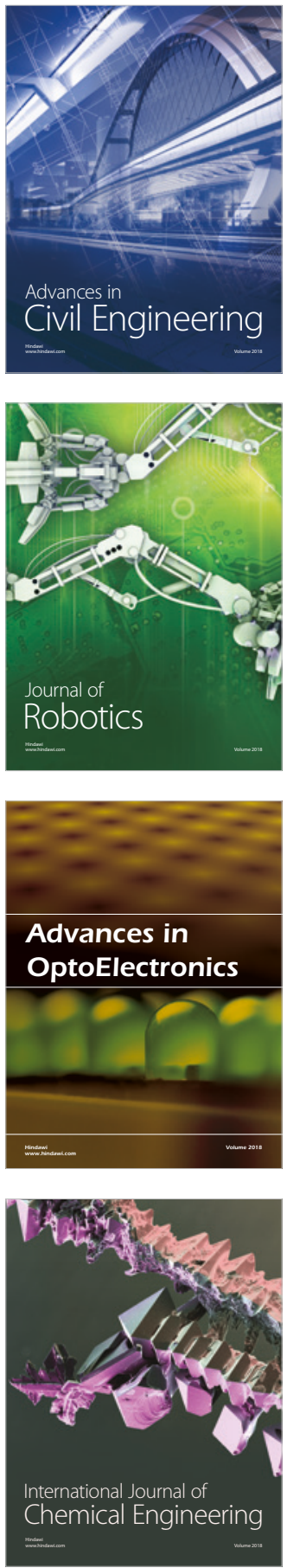

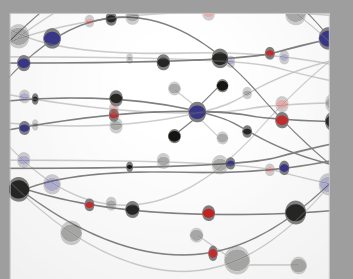

\section{Rotating \\ Machinery}

The Scientific World Journal

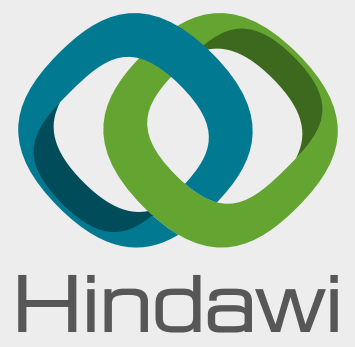

Submit your manuscripts at

www.hindawi.com
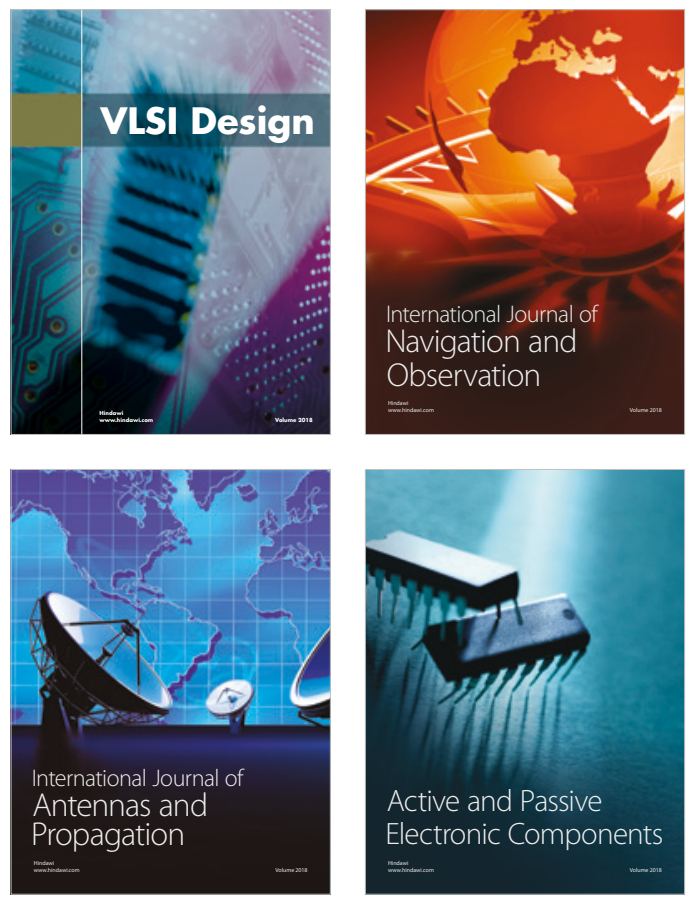
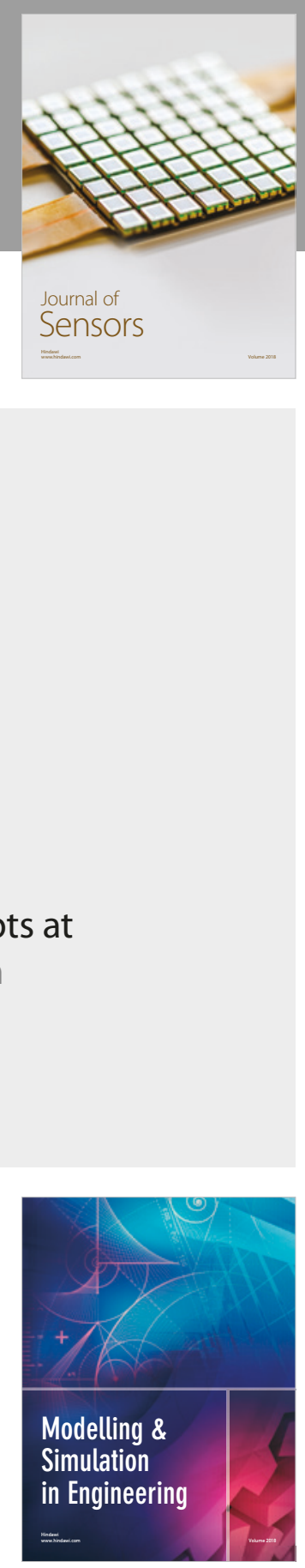

\section{Advances \\ Multimedia}
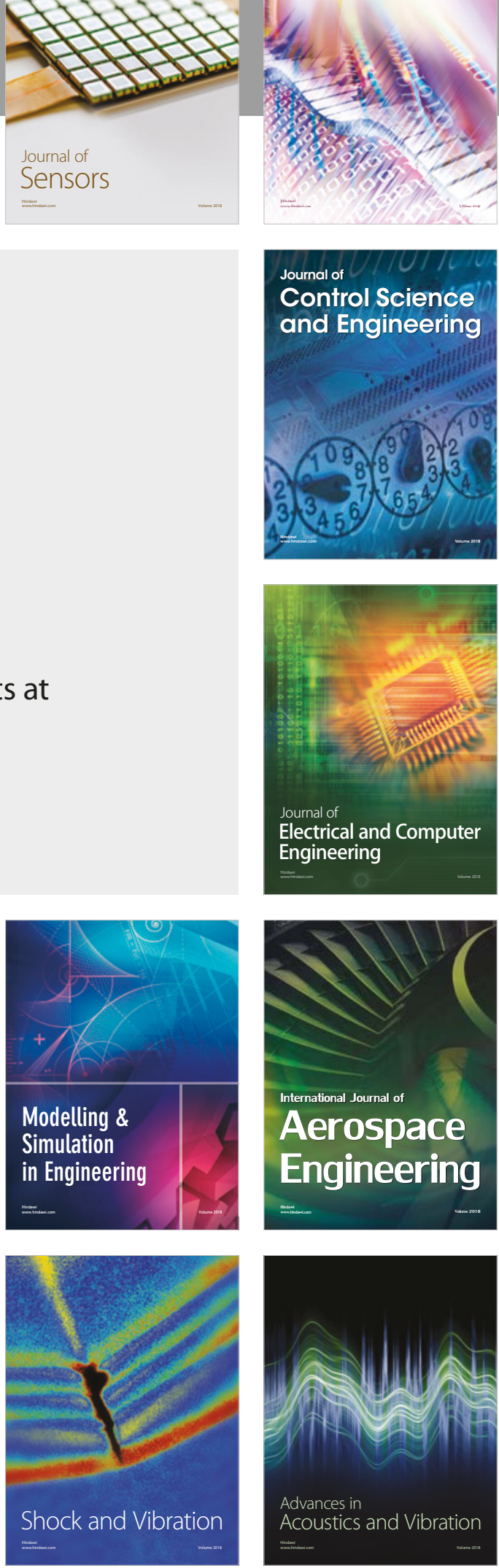